\title{
Antepartum Myomectomy
}

\author{
Tabassum Parveen ${ }^{1}$, Firoza Begum ${ }^{2}$, Nahreen Akhtar ${ }^{3}$ Umme Kulsum ${ }^{4}$. \\ 1. Associate Professor. Fetomatemal medicine wing, Department of Obs \& Gynae, BSMMU 2. Professor, Fetomatemal Medicine wing, Department \\ of Obs \& Gynae, BSMMU ${ }^{3}$. Associate Professor, Fctomaternal Medicine wing, Department of Obs \& Gynae, BSMMU ${ }^{4}$ Med ical Officer, \\ fetomatemal Medicine wing, Department of Obs \& Gynae. BSMMU
}

\begin{abstract}
:
Myomectomy perforned during pregnancy is a rarity. Literature survey showed few case reports on antepartum myomec-tomy. Though controversy persists among reports, but somc case series reported the successfull antepartum myomectomy in carefully selected patients. Sometimes surgery is planned for ovarian tumour but incidentally found fibroid during surgery as itis also done in the present case. We here present a case report of a 28 years primigravida woman who had undergone laparotomy for antenatally diagnosed case of ovarian tumour at 13 weeks of gestation under spinal anesthesia. But on opening the abdominal cavity a large sub-serous degenerated fibroid was found to arise from the fundus. Myomec-tomy was performed ensuring minimum handling of the uterus. The patient had an uneventful postoperative period and was discharged on 8th post operative day. She delivered a healthy male baby of $3 \mathrm{~kg}$ at 39 weeks of gestation with good apgar score.
\end{abstract}

Key ivords : Myomectomy, pregnancy.

[BSMMU J $2013 ; 6(2): 104-107]$

\section{Introduction:}

The prevalence of leiomyoma during pregnancy is reported as $2 \%$.' Though Leiomyomata tend to grow during pregnancy but rarely interferes with the growing pregnancy. Most of the time during pregnancy, uterine leiomyoma remain asymptomatic but occasionally may be associated with complications like red degeneration and an increased frequency of spontaneous abortion, preterm labor, premature rupture of fetal membranes, antepartum hemorrhage, malpresentations, obstructed labour, caesarean section and postpartum hemorrhage. ${ }^{1 \cdot 3}$ Generally, myomectomy is avoided during pregnancy because of the risk of haemorrhage due to increased vascularity, abortions, hazards of anesthetic agents. Management of uterine leiomyoma during pregnancy is largely expectant and its surgical removal is generally delayed until after delivery. ${ }^{4.7}$ However, in selected cases myomectomy may become necessary during pregnancy. ${ }^{8}$ Though controversy persists among reports of myomectomy being performed during pregnancy ${ }^{1}$, but some case series reported the successful antepartum myomectomy in

Address for Correspondence: Dr. Tabassum Parveen Associate Professor Fetomaternal medicine wing, Dept of Obs \& Gynae .BSMMU

Mobile no: 01911348808,E-mail address: dr_parveent@yahoo.com carefully selected patients. ${ }^{1.9}$ We here present a case of successful myomectomy with good feto-maternal outcome for a large fibroid which was diagnosed as ovarian tumour before surgery.

\section{Case Rrport:}

Case- A 28-year primigravida woman got herself admitted in fetomaternal medicine wing of the department of Obstetrics and Gynaecology of Banga Bandhu Sheikh Mujib Medical University on $10^{\text {th }}$ March, 2011 at 11 weeks of pregnancy with a mass in the lower abdomen along with pain and discomfort in lower abdomen. On examination patient was found ill looking, anaemic and normotensive. On per abdominal examination a solid non tender mass of about $12 \times 12 \mathrm{~cm}$ in diameter was found occupying the right lumber and hypogastric region. Ultrasonogram of the lower abdomen showed a solid, multiloculated mass at the right side of the uterus suggestive of ovarian tumour along with an intrauterine viable pregnancy of 13 weeks. On investigations, Hb level was $10.1 \mathrm{gm} / \mathrm{dl}$, blood sugar 2 hours after $75 \mathrm{gm}$ glucose was $9.1 \mathrm{mmol} / \mathrm{l}$. Tumour marker CA-125 level was done and found nomal (25 IU/L). Clinically she was diagnosed as a case of 13 weeks pregnancy with gestational diabetes mellitus (GDM) with ovarian tumour. Her blood sugar 
was well controlled with dietary manipulation. After counseling with the patient and patient's party about the risk of surgery on pregnancy, laparotomy was proposed and done at 13 weeks of pregnancy under spinal anesthesia. Per- operatively uterus was found about 14 week's size. A subserous fibroid measuring about $12 \times 12 \mathrm{~cm}$ in diameter found to arise from the right anterosuperior aspect of the fundus of the uterus with features of degeneration. The stalk of the mass was about $4 \mathrm{~cm}$. Both ovaries and tubes were unremarkable. Myomectomy was done with great care ensuring minimum handling of the uterus. Myoma bed was quickly closed and haemostasis was ensured. Blood loss was minimum and one unit of blood was transfused peroperatively. The specimen was sent for histopathology. Post operatively she was given Injection Proluton depot $(250 \mathrm{mg}) 2$ ampoules $\mathrm{I} / \mathrm{M}$ to prevent uterine contraction. $\mathrm{Hb}$ level was noted $10 \mathrm{gm} / \mathrm{dl}$ on $2^{\text {nd }}$ post operative day. The patient had an uneventful postoperative period and she was discharged on $8^{\text {th }}$ post operative day with the advice to attend the antenatal clinic for regular follow up. Rest of her antenatal period was uneventful. She was readmitted at 39 weeks of gestation with slight lower abdominal pain. On admission bishop score was found favourable and pelvis was adequate. Decision was taken to allow vaginal delivery under close supervision. She went into spontaneous labour on the day of admission and a male baby of $3 \mathrm{~kg}$ with good Apgar score was delivered vaginally. Placenta and membranes were expelled out spontaneously and there was no post partum haemmorhage. As her post natal period was uneventful the patient was discharged on $2^{\text {nd }}$ postnatal day. The 6 weeks post-natal visit was unremarkable.

\section{Discussion:}

Myomectomy performed during pregnancy remains a rarity. Literature survey showed a few case reports. Sometimes surgery is planned for ovarian tumour but incidentally found fibroid during surgery as it happened in the present case also. In the present case before surgery, clinical and sonographical presentation was in favour of ovarian tumour. As it appeared multiloculated, solid tumour on songraphy, laparotomy was planned. An almost similar case was reported by Chisara and colleagues where a 30 year old woman presented at 19 weeks pregnancy with grossly distended tense abdomen and sonographic diagnosis of ovarian tumor. But laparotomy revealed a $32 \mathrm{~cm}$ degenerating subserosal uterine fibroid co-existing with an intrauterine pregnancy. Myomectomy was successfully performed. The subsequent antenatal period was uneventful with a spontaneous vaginal delivery of a female baby at 38 weeks. ${ }^{10}$ During surgery we found the stalk of the myoma was about $4 \mathrm{~cm}$ in diameter. Burton et al recommended that myomectomy in pregnancy should be confined to symptomatic myomas which are pedunculated with a stalk of 5-cm diameter or less. ${ }^{9}$ Pain in myoma with pregnancy is mostly due to degeneration and expectant management with bed rest, hydration, nonsteroid anti inflammatory drugs (NSAID) for short periods or opiods as analgesics are the key to management. However, medical treatment sometimes fails and myomectomy appears to be inevitable. ${ }^{11,} 12$ Myomectomy as a treatment for the syndrome of painful myomas in pregnancy has been explored in the literature. ${ }^{11-13}$ In most of the available case reports the decision of myomectomy was made mostly for recurrent attack of intractable pain. Hakan et al presented two such case reports, the first case was of a 35 years old woman, para 4, presented with pelvic pain at 19 weeks of gestation and ultrasonographic examination showed a solid mass of 12 centimeters in diameter adjacent to the gravid uterus. Magnetic resonance imaging revealed the mass to be of uterine origin. Though initially expectant management was given but due to progressive abdominal pain decision of laparotomy was taken at 21 week of the pregnancy and myomectomy of a fundal pedunculated, degenerating myoma of nearly 15 -centimeter in diameter was done. Following myomectomy pregnancy progressed to term without complications and a 3400 -gram male baby was delivered by elective cesarean section. Neither neonatal nor puerperal complication occurred. The second case presented with a calcified solid mass of 10 centimeters in diameter during routine ultrasonographic examination in a 32 years-old primigravida woman at 12 weeks' gestation. In further evaluation of this asymptomatic mass, MRI showed large myoma situated in the anterior aspect of the gravid uterus. Due to recurrent attacks of pelvic pain laparotomy was planned and myomectomy of 12 centimeters myoma with a short, thick pedicle was done at 19 weeks' of gestation. No complications were encountered during the rest of the pregnancy. A healthy boy of 4000 grams was delivered by elective cesarean section. ${ }^{14}$ In the present study patient had complaints of occasional lower abdominal pain and sometimes need to take NSAIDs but it was never severe in nature. Preoperatively as the diagnosis was ovarian tumour, pain was thought due to 
partial twisting of the tumour which also mandates for laparotomy. During surgery huge degeneration of the myoma was noted and explained the underlying pathology of the pain in the patient.

In this case during laparotomy decision of myomectomy was taken considering several factors like large and rapidly growing tumour, huge degeneration, subserous in nature and having pedicle around $4 \mathrm{~cm}$. Burton et al recommended that myomectomy in pregnancy should be confined to symptomatic myomas which are pedunculated with a stalk of 5-cm diameter or less. ${ }^{9}$ Mollica et al suggested additional criteria in asymptomatic patients for elective myomectomy that consisting large or rapidly growing myomas, large or medium myomas located in the lower uterine segment or deforming placenta. According to these criteria they operated 18 patients and reported good fetoneonatal outcome with no abortions, while in group of 88 pregnancies followed by conservative regimen, $13.6 \%$ abortion rate was observed. ${ }^{15}$ Isabu and colleagues of Nigeria presented a case report where successful myomectomy was done on a 28 -year-old primigravid patient having a large fundally sited multi lobulated fibroid extending up to the right hypochondrium having huge degenerative change. ${ }^{16}$ Laparotomy findings of the tumour are almost similar to the present case, where myoma was noted to arise from the fundus and extended almost upto the left hypochondrium. Myomectomy followed by closure of the myomectomy bed was not much difficult as noted in this case as well as in most of the other available studies. In this case the myoma was of subserous verity which may explain the easy enucleation and closure of the myoma bed. This view is also supported in the studies of Chisara and colleagues. In the present study blood loss was noted minimum during surgery. Hypercoagulability in pregnancy might have contributed to the ease in achieving hemostasis. The ease with which the fibroid was removed and the minimal measures used to obtain hemostasis contributed to the safety of the procedure. The immediate post natal period was smooth and the rest of the antenatal periods was uneventful in the present case and progressed to term without complications. Most of the available studies had almost similar results like the prospective cohort study of Lolis et al who reported myomectomy of 13 women and in $92 \%$ of these cases, successful myomectomy was performed and the pregnancy progressed to term without further complications. ${ }^{1}$ Pregnancy also progressed normally in the patient of Isabu and colleagues, Wittich and colleagues of the Department of Obstetrics/Gynecology, Tripler Army Medical Center, Honolulu, USA. ${ }^{16}$

Most of the available evidence showed that the mode of delivery following myomectomy was elective caesarean section. ${ }^{11,16}$ The patient of the present study had spontaneous onset of labour and as clinical parameters were favourable, so she was allowed for vaginal delivery under close supervision and patient delivered a healthy male baby of $3 \mathrm{~kg}$. Chisara Umezurik and Paul Feyi-Waboso in their patient also had spontaneous vaginal delivery of a female baby at 38 weeks of their patient. ${ }^{10}$ In both the cases post natal period was uneventful. This signifies the fact that vaginal delivery can be allowed and considered to be safe in cases of myomectomy during pregnancy specially if it is sub-serous verity.

\section{Conclusion:}

A degenerating pedunculated subserous uterine fibroid may mimic an ovarian tumor in pregnancy and obstetricians should be aware of it while considering laparotomy. Although most cases of uterine fibroids in pregnancy can be managed conservatively, antepartum myomectomy may be necessary in selected cases. This report as well as available published data supports the safety of myomectomy during pregnancy in selected cases.

\section{References:}

1. Lolis DF, Kalantaridou SN, Makrydimas G, Sotiriadis A, Navrozoglu I, Zikopoulos K, Paraskevaidis EA. Successful myomectomy during pregnancy. Human Reproduction 2003; 18:1699-1702, doi: 10.1093/humrep/deg318

2. Brown D, Fletcher HM, Myrie MO, Reid M. Cesarean myomectomy- a safe procedure. A retrospective case controlled study. Obstet Gynecol 1999; 19:139-141.

3. Ikedife D. Surgical challenge of myomectomy at cesarean section. Nigerian Journal of Surgical Sciences 1993; 3:15-17.

4. Kwawukume EY. Myomectomy during cesarean section. Int J Gynecol Obstet 2002; 76:183-184. doi: 10.1016/S00207292(01)00586-0.

5. Ezechi OC, Kalu BKE, Okeke PE, Nwokoro CO. Inevitable cesarean myomectomy: A case report. Trop J Obstet Gynecol. $2003 ; 20: 159-160$.

6. Ehigiegba AE, Evbuomwan CE. Inevitable caesarean myomectomy. Trop J Obstet Gynecol 1998; 15:62.

7. Roman AS, Tabsh KM. Myomectomy at time of cesarean delivery; a retrospective cohort study. BMC Pregnancy and childbirth 2004; 4:14. doi: $10.1186 / 1471-2393-4-14$ 
8. Michalas SP, Oreopoulou FV, Papageorgiou JS. Myomectomy during pregnancy and caesarean section. Human Reproduction $1995 ; 10: 1869-70$.

9. Burton CA, Grimes DA, March CM. Surgical management of leiomyomata during pregnancy. Obstet Gynecol 1989; 74: 707-9.

10. Chisara Umezurike and Paul Feyi-Waboso. Successful myomectomy during pregnancy: A case report. Reprod Health 2005; $2: 6$. doi: $10.1186 / 1742-4755-2-6$.

11. Wittich AC, Salminen ER, Yancey MK, Markenson GR. Myomectomy during early pregnancy. Mil Med 2000; 165: 162-4.

12. De Carolis S, Fatigante G, Ferrazzani S, Trivellini C, De Santis L, Mancuso S, Caruso A. Uterine myomectomy in pregnant women. Fetal Diagn Ther 2001; 16: 116-9
13. Katz V, Dotters DJ, Droegenueller W. Complications of uterine leiomyomas in pregnancy. Obstet Gynecol 1989; 73: 593- 6.

14. Hakan KANIT, Dilek ASLAN, Pek AYDAL, Nilgun D CLE, Gulcin U UREL. Myomectomy during Pregnancy. Perinatoloji Dergisi Cilt 2001; 9: 57-59.

15. Mollica G, Pittini L, Minganti E, Perri G, Pansini F. Elective uterine myomectomy in pregnant women. Clin Exp Obstet Gynecol 1996; 23: 168- 72 .

16. Isabu P, Eigbefoh J, Okogbo F, Okunsanya S, Eifediyi R. Myomectomy during second trimester pregnancy: a case report. Niger Postgrad Med J. 2010 Dec; 17:324-6. 